\title{
Loss of CD10/NEP Expression in the Pulmonary Carcinogenesis
}

\author{
Nahye Myong, M.D. \\ Department of Anatomic Pathology, Dankook University College of Medicine, Cheonan, Korea
}

Purposes: The cell surface metalloproteinase CD10/ neutral endopeptidase 24.11 (NEP) hydrolyzes a variety of peptide substrates and reduces cellular responses to specific peptide hormones. CD10/NEP has been recognized as modulating peptide-mediated proliferation of lung carcinomas and the normal airway epithelium. The purposes of this study are to evaluate the expression of CD10/NEP in human lung cancers, including non-small cell lung carcinoma (NSCLC) and small cell lung carcinoma (SCLC), and to correlate its expression with several clinicopathologic parameters, including proliferative activity.

Materials and Methods: CD10/NEP expression and proliferative activity were evaluated by immunohistochemistry in 55 formalin-fixed and paraffin-embedded NSCLC and SCLC specimens, using anti-Human CD10/ NEP and Ki-67 primary antibodies. The correlations between CD10/NEP expression and either Ki-67 proliferative activity or several clinicopathologic parameters were analyzed by chi-square test or Fisher's exact test.

\section{INTRODUCTION}

CD10/NEP (neutral endopeptidase) is expressed on normal lymphoid progenitors, mature polymorphonuclear leukocytes, and a variety of nonhematopoietic cell types including bronchial and alveolar epithelia $(1,2)$. It functions in multiple organ systems to down-regulate induced responses to peptide hormones. CD10/NEP, which is expressed at high levels in the lung, similarly regulates responses to substance $\mathrm{P}$, the primary mediator of neurogenic inflammation of the respiratory tract. The bombesin-like peptides (BLPs) are another family of peptides that are potent mitogens for normal bronchial epithelial and neuroendocrine cells and fibroblasts (3). These peptides also stimulate the growth of many small cell lung carcinoma (SCLC) and non-small cell lung carcinoma (NSCLC) cell lines, which feature an autocrine loop consisting of tumor cells secreting BLP, expressing BLP receptors, and responding to

Correspondence: Nahye Myong, Department of Anatomic Pathology, Dankook University College of Medicine San 29, Anseodong, Cheonan-si, Chungnam 330-714, Korea. (Tel) 041-550-3891,

(Fax) 041-561-9127, (E-mail) myongnh @anseo.dankook.ac.kr

The present research was conducted by the research fund of Dankook University in 2001.

Received December 27, 2001, Accepted February 8, 2002
Results: Most NSCLC $(76 \%)$ and SCLC $(80 \%)$ cases showed loss of CD10/NEP expression in the tumor cells, whereas the bronchial and alveolar epithelia and stromal fibroblasts in the adjacent healthy lung revealed strong expression of CD10/NEP. Its expression was not correlated with proliferative activity or any of the clinicopathologic parameters except for age. Only in terms of topographical expression was CD10/NEP expression found to be inversely correlated with $\mathrm{Ki}-67$ proliferative activity.

Conclusion: These results suggest that loss of CD10/ NEP expression may be important in the pulmonary carcinogenesis of both NSCLCs and SCLCs, which is topographically related to NSCLC proliferative activity, especially in the squamous cell type. (Cancer Research and Treatment 2002;34:17-22)

Key Words: CD10/NEP, Loss of expression, Pulmonary carcinogenesis

BLP stimulation with increased proliferation (4).

Many lung cancers are stimulated by an autocrine/paracrine system of neuroendocrine peptide hormones $(5,6)$. In the normal lung, CD10/NEP plays a physiological role in degrading the biologically active peptides, including all peptide hormones implicated in autocrine growth stimulation of lung cancer. Cigarette smoke was shown to decrease the activity of CD10/NEP, indicating that the reduction of CD10/NEP contributes to the dysregulation of the peptide autocrine system. A previous study indicated that the damage to enzymes is mediated by free radicals (7). Thus, smokers experience increased production and decreased destruction of neuropeptides, which serve as autocrine/paracrine growth factors in the pathogenesis of lung cancer.

In a study of primary human lung NSCLCs and the cell lines, CD10/NEP expression was reported to be inversely correlated with cellular proliferation (8). A recent report also suggests CD10/NEP gene expression might be used as a significant indicator of prognosis, because the patients with CD10/NEP gene expression survived much longer than those with CD10/NEP gene (-) tumors (9). However, CD10/NEP expression has been only rarely evaluated in primary lung tumors and adjacent uninvolved lungs of patients with lung cancer $(8,10)$.

In our immunohistochemical study, we characterized CD10/ NEP expression in primary lung cancers, including SCLC and NSCLC, determined its relationship to cellular proliferation, 
and tried to identify any prognostically significant clinicopathologic parameters. From this investigation we determined the role of CD10/NEP expression in pulmonary carcinogenesis.

\section{MATERIALS AND METHODS}

\section{1) Tissue samples and clinical data}

Tissues were obtained from 45 resected specimens and 10 bronchoscopic biopsies of 55 lung cancer patients, including samples from the patients' adjacent normal lungs. All were formalin fixed and paraffin embedded. Of 45 NSCLC and 10 SCLC specimens comprising the total study sample, 2 NSCLC and 8 SCLC tissues were obtained by bronchoscopic biopsies. The slides were stained with hematoxylin and eosin, and the pathological diagnoses of histologic grade and type were confirmed by the study pathologist (N.M.). We reviewed the hospital records of all 55 patients to determine the clinicopathologic variables such as age, sex, smoking history, TNM stage (in NSCLC), and tumor extent (in SCLC). The pathologic staging of NSCLC and SCLC was assessed according to the Tumor-Node-Metastasis Classification of AJCC staging system (1997) and the Veterans' administration lung study group (VALSG) staging system (1973), respectively.

\section{2) Immunohistochemistry}

Four micrometer thick tissue sections were cut from formalin-fixed, paraffin-embedded blocks of tumor and normal adjacent lung and placed on silane-coated slides. Deparaffinization of all sections was performed through a series of xylene baths, and rehydration was achieved through graded alcohols. The sections were microwaved in $10 \mathrm{mM}$ citrate buffer at $90^{\circ} \mathrm{C}$ for $10 \mathrm{~min}$ and were treated with $3 \% \mathrm{H}_{2} \mathrm{O}_{2}$-PBS solution to reduce endogenous peroxidase activity. They were then incubated with normal bovine serum to reduce nonspecific antibody binding and subsequently subjected to primary antibody reactions. The primary antibodies used in this study were mouse anti-Human-CD10 monoclonal antibody (NCLCD10-270, Novocastra, Newcastle upon Tyne, UK) and rabbit anti-Human-Ki-67 polyclonal antibody (A047, DAKO, Carpinteria, CA), respectively, both at a dilution of $1: 100$. After reaction with the primary antibodies for 1 hour at room temperature, detection of the immunoreactive sites was carried out by the avidin-biotin-peroxidase complex method using LSAB kit (DAKO). The sections were subjected to a color reaction with 3,3-diaminobenzidine tetrahydrochloride containing $3 \% \mathrm{H}_{2} \mathrm{O}_{2}$ in Tris buffer and were lightly counterstained with Mayer's hematoxylin.

The immunostained cells were considered positive for CD10/ NEP and Ki-67 only when distinct membranous and nuclear stainings were identified, respectively. The NSCLCs and SCLCs were regarded positive for CD10/NEP expression when more than $5 \%$ of the stained cells demonstrated membranous positivity, and negative when less than $5 \%$ demonstrated such positivity. Cases were considered positive for Ki-67 overexpression when at least $10 \%$ of the tumor cells exhibited nuclear immunoreactivity. The $5 \%$ and $10 \%$ limits were chosen as they equated to the median values for each immunostaining.

\section{3) Statistical analysis}

The significances of the relationship of CD10/NEP expression with Ki-67 proliferative activity and of the difference in CD10/NEP expression between two categorical clinicopathologic variables were analyzed by chi-square test or Fisher's exact test (SPSS 10.0). A $p$ value less than 0.05 was defined as statistically significant.

\section{RESULTS}

\section{1) Clinicopathologic data}

Patient profiles are given in Tables 1, 2. The NSCLC group consisted of 37 male and 8 female patients, all 10 SCLC patients were male. The mean age was 59.9 years (range 31 83 ) and 59.6 years (range $51 \sim 75$ ) in the NSCLC and SCLC groups, respectively. The NSCLC group included 31 smokers and 8 non-smokers and all 10 SCLC patients were smokers. The pathological staging of the 43 resected NSCLCs revealed 15 cases of stage 1,9 of stage 2 , and 19 of stage 3. Pathological T stages were pT1 in 8 cases, pT2 in 18 , pT3 in 13, and pT4 in 4 . The NSCLCs were histologically classified as 25 squamous cell carcinomas (SCC), 15 adenocarcinomas (ADC), 3 large cell carcinomas (LCC), 1 bronchioloalveolar carcinoma (BAC), and 1 adenosquamous carcinoma (ASC). The tumors were graded as 6 cases of grade 1 (well differentiated), 23 of grade 2 (moderately differentiated), and 9 of grade 3 (poorly differentiated). The 10 SCLC cases were staged as 6 limited and 4 extensive diseases.

\section{2) CD10/NEP and Ki-67 immunoreactivity in the non- neoplastic lung tissues}

CD10/NEP expression was very prominent in the non- neoplastic alveolar and airway epithelia (Fig. 1) and in the stromal

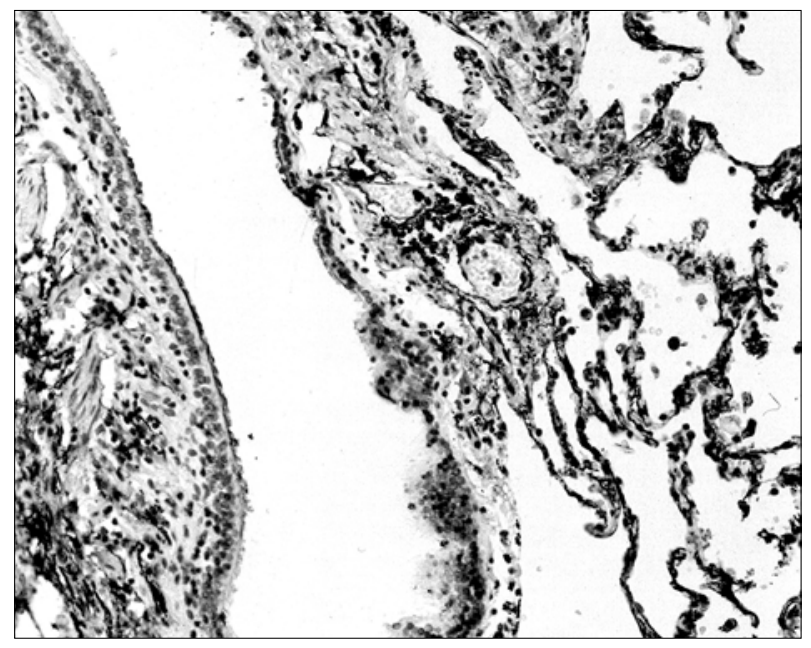

Fig. 1. Immunohistochemical staining for CD10/NEP in the normal lungs reveals diffuse and prominent expression of the surface enzyme in the alveolar and bronchial surface epithelial linings $(\times 200)$. 
fibroblasts. However, most of the few normal bronchial and bronchiolar cells that were immunoreactive for Ki-67 were found in the basal layers.

3) CD10/NEP expression in NSCLCs and SCLCs, and correlation with clinicopathologic features (Tables 1, 2)

Thirty-four cases $(76 \%)$ of the 45 NSCLCs and 8 (80\%) of the 10 SCLCs revealed markedly reduced or absent immunoreactivity for CD10/NEP protein expression (Fig. 2, 3). For NSCLCs and all lung carcinomas including SCLCs, there was no correlation between the loss of CD10 expression and most clinicopathologic parameters, including sex, smoking history, stage, tumor size (pT), and histologic grade and type, except for age. The patients under 59 years showed significantly higher loss of CD10/NEP expression than those over 60 years.

Table 1. Correlations between CD10/NEP expression and clinicopathologic features in non-small cell lung carcinomas

\begin{tabular}{|c|c|c|c|c|}
\hline \multirow{2}{*}{$\begin{array}{c}\text { Clinicopathologic } \\
\text { features }\end{array}$} & \multirow{2}{*}{$\begin{array}{l}\text { No. of } \\
\text { cases }\end{array}$} & \multicolumn{2}{|c|}{ CD10 immunoreactivity } & \multirow[t]{2}{*}{$p$ value* } \\
\hline & & Negative $(\%)$ & Positive $(\%)$ & \\
\hline \multicolumn{5}{|l|}{ Age } \\
\hline Age $\leq 59$ yrs & 20 & $18(90)$ & $2(10)$ & 0.044 \\
\hline Age $>59$ yrs & 25 & $16(64)$ & $9(36)$ & \\
\hline \multicolumn{5}{|l|}{ Sex } \\
\hline Male & 37 & $27(73)$ & $10(27)$ & 0.657 \\
\hline Female & 8 & $7(88)$ & $1(12)$ & \\
\hline \multicolumn{5}{|l|}{ Smoking history } \\
\hline Smokers & 31 & $22(71)$ & $9(29)$ & 0.653 \\
\hline Non-smokers & 8 & $7(88)$ & $1(12)$ & \\
\hline \multicolumn{5}{|l|}{ Stage } \\
\hline 1 & 15 & $12(80)$ & $3(20)$ & 0.719 \\
\hline $2 \sim 3$ & 28 & $20(71)$ & $8(29)$ & \\
\hline \multicolumn{5}{|l|}{ pT } \\
\hline $1 \sim 2$ & 26 & $22(85)$ & $4(15)$ & 0.058 \\
\hline $3 \sim 4$ & 17 & $10(59)$ & $7(41)$ & \\
\hline \multicolumn{5}{|l|}{ Grade } \\
\hline $1 \sim 2$ & 29 & $22(76)$ & $7(24)$ & 0.584 \\
\hline 3 & 9 & $6(67)$ & $3(33)$ & \\
\hline \multicolumn{5}{|l|}{ Histologic type } \\
\hline $\mathrm{SCC}^{\dagger}$ & 25 & $19(76)$ & $6(24)$ & $0.938^{\ddagger}$ \\
\hline $\mathrm{ADC}^{\S}$ & 15 & $10(67)$ & $25(33)$ & \\
\hline $\mathrm{LCC}^{\|}$ & 3 & $3(100)$ & $0(0)$ & \\
\hline $\mathrm{BAC}^{\pi}$ & 1 & $1(100)$ & $0(0)$ & \\
\hline $\mathrm{ASC}^{* *}$ & 1 & $1(100)$ & $0(0)$ & \\
\hline Total & 45 & $34(76)$ & 11 (29) & \\
\hline
\end{tabular}

*Chi-square test or Fisher's exact test, ${ }^{\dagger}$ Squamous cell carcinoma, ${ }^{*} \mathrm{p}$ value between the percentages of CD10/NEP immunoreactivity in squamous versus non-squamous carcinoma, ${ }^{\S}$ Adenocarcinoma, "Large cell carcinoma, "Bronchioloalveolar carcinoma, **Adenosquamous carcinoma

\section{4) The relationship between CD10/NEP expression and Ki-67 proliferative activity (Table 3)}

Although there was no statistical relationship between loss of $\mathrm{CD} 10 / \mathrm{NEP}$ expression and $\mathrm{Ki}-67$ proliferative activity in NSCLCs and SCLCs, 4 cases among the 25 NSCLCs of squamous type (16\%) revealed topographically regional variations in CD10/NEP immunostaining. The loss of CD10/NEP expres-

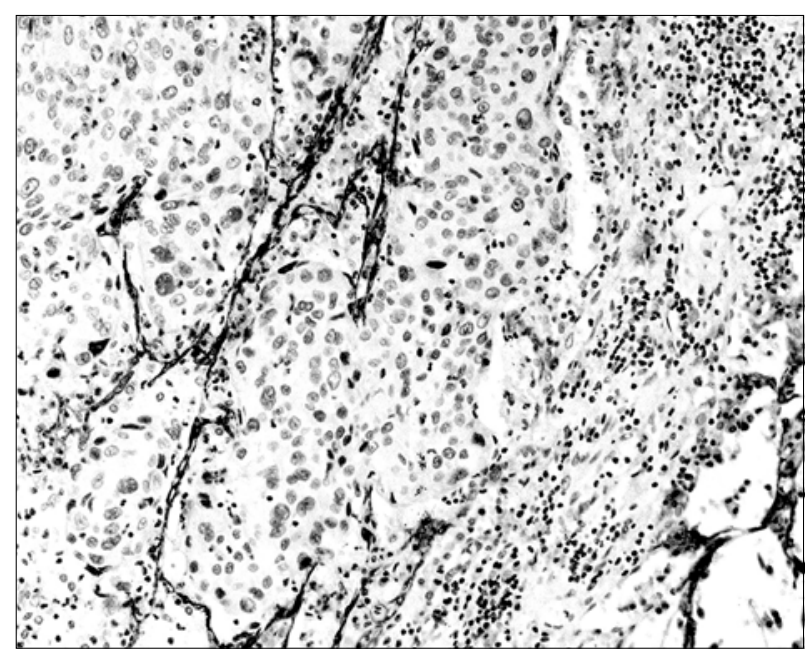

Fig. 2. Immunohistochemical expression for CD10/NEP is markedly reduced or absent in the tumor cells of non-small cell lung carcinoma in contrast to the alveolar lining cells showing CD10/NEP expression $(\times 200)$.

Table 2. Correlation between CD10 immunoreactivity and clinicopathologic features in the lung carcinomas including NSCLC and SCLC

\begin{tabular}{|c|c|c|c|c|}
\hline \multirow{2}{*}{$\begin{array}{l}\text { Clinicopathologic } \\
\text { features }\end{array}$} & \multirow{2}{*}{$\begin{array}{l}\text { No. of } \\
\text { cases }\end{array}$} & \multicolumn{2}{|c|}{ CD10 immunoreactivity } & \multirow{2}{*}{$\mathrm{p}$ value* } \\
\hline & & Negative (\%) & Positive (\%) & \\
\hline \multicolumn{5}{|l|}{ Age } \\
\hline Age $\leq 59$ years & 24 & $22(92)$ & $2(8)$ & 0.026 \\
\hline Age $>59$ years & 31 & $20(65)$ & $11(35)$ & \\
\hline \multicolumn{5}{|l|}{ Sex } \\
\hline Male & 47 & $35(74)$ & $12(26)$ & 0.664 \\
\hline Female & 8 & $7(87)$ & $1(13)$ & \\
\hline \multicolumn{5}{|l|}{ Smoking history } \\
\hline Smokers & 41 & $30(73)$ & $11(27)$ & 0.660 \\
\hline Non-smokers & 8 & $7(87)$ & $1(13)$ & \\
\hline \multicolumn{5}{|l|}{ Stage $^{+}$} \\
\hline Limited ds. $^{\ddagger}$ & 6 & $4(67)$ & $2(33)$ & 0.467 \\
\hline Extensive ds. & 4 & $4(100)$ & $0(0)$ & \\
\hline Total & 55 & $42(76)$ & $13(24)$ & \\
\hline
\end{tabular}

*Fisher's exact test, ${ }^{\dagger} 10$ cases of SCLC were staged as limited and extensive diseases. ${ }^{\ddagger}$ Disease 
Table 3. Correlation between CD10/NEP expression and Ki-67 proliferative activity in all lung carcinomas (3-1), NSCLCs (3-2) and SCLCs (3-3)

$(3-1)$

\begin{tabular}{lcccc}
\hline CD10/NEP & $\begin{array}{c}\text { No. of } \\
\text { expression } \\
\text { cases }\end{array}$ & \multicolumn{2}{c}{ Ki-67 immunoreactivity } & p value* \\
\cline { 3 - 5 } & & Negative (\%) & Positive (\%) & \\
\hline Positive & 13 & $4(31)$ & $9(69)$ & 0.863 \\
Negative & 42 & $14(33)$ & $28(67)$ & \\
\hline
\end{tabular}

${ }^{*}$ Chi-square test

\begin{tabular}{lcccc}
\hline $\begin{array}{l}\text { CD10/NEP } \\
\text { expression }\end{array}$ & $\begin{array}{c}\text { No. of } \\
\text { cases }\end{array}$ & \multicolumn{2}{c}{ Ki-67 immunoreactivity } & p value* \\
\cline { 3 - 5 } & & Negative (\%) & Positive (\%) & \\
\hline Positive & 11 & $3(27)$ & $8(73)$ & 0.720 \\
Negative & 34 & $13(38)$ & $21(62)$ & \\
\hline
\end{tabular}

*Fisher's exact test

(3-3)

\begin{tabular}{lcccc}
\hline $\begin{array}{l}\text { CD10/NEP } \\
\text { expression }\end{array}$ & $\begin{array}{c}\text { No. of } \\
\text { cases }\end{array}$ & \multicolumn{2}{c}{ Ki-67 immunoreactivity } & p value* \\
& & Negative (\%) & Positive (\%) & \\
\hline Positive & 2 & $1(50)$ & $1(50)$ & 0.378 \\
Negative & 8 & $1(12)$ & $7(88)$ & \\
\hline
\end{tabular}

*Fisher's exact test

sion was topographically inversely related with Ki-67 proliferative activity. The CD10/NEP expression was found more frequently in the more well-differentiated central portions of the squamous carcinoma clusters, whereas the less well-differentiated peripheral portions were immunostained mainly with Ki-67 proteins (Fig. 4). The 2 SCLC cases exhibiting CD10/NEP expression revealed no topographical relationship with $\mathrm{Ki}-67$ proliferative activity.

\section{DISCUSSION}

CD10/NEP is a cell surface peptidase whose physiological role is to inactivate bioactive peptides such as gastrin-releasing peptide, bradykinin, gastrin, tachykinin, and other peptides $(11,12)$. It is highly expressed in the adult lung, especially in pulmonary epithelial cells where it regulates bronchoconstriction and tissue response to peptides (13). Cigarette smoke has been shown to inactivate the enzyme, CD10/NEP, expression and thereby increase peptide production in the lung (7). Therefore, smokers have increased levels of neuropeptides, which serve as autocrine/paracrine growth factors in the pathogenesis of lung cancer. Heavy smoking has also been reported to affect p53 mutations in NSCLC (14).

Both SCLC and NSCLC express bombesin-like peptides

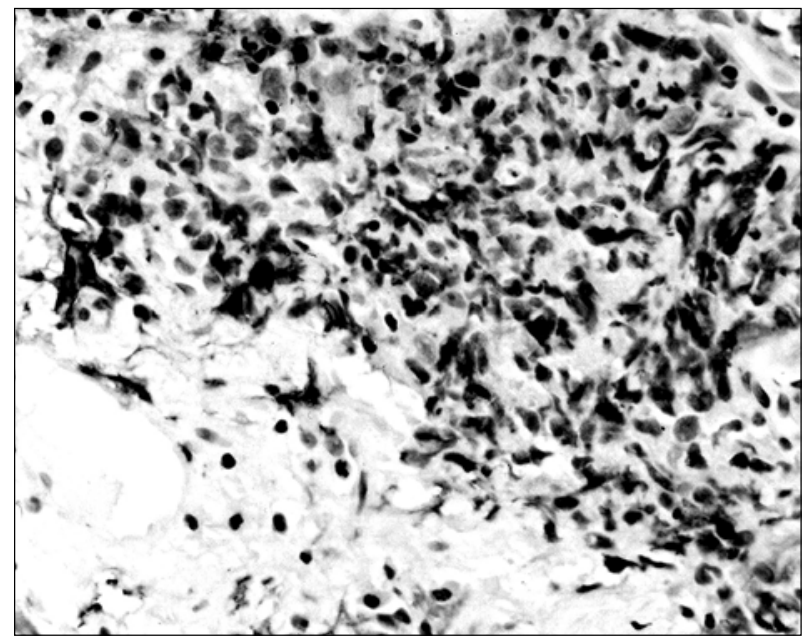

Fig. 3. Loss of CD10/NEP protein expression is immunohistochemically observed in most small cell carcinoma cells compared to the adjacent stromal fibroblasts showing CD10/NEP immunoreactivity $(\times 400)$.
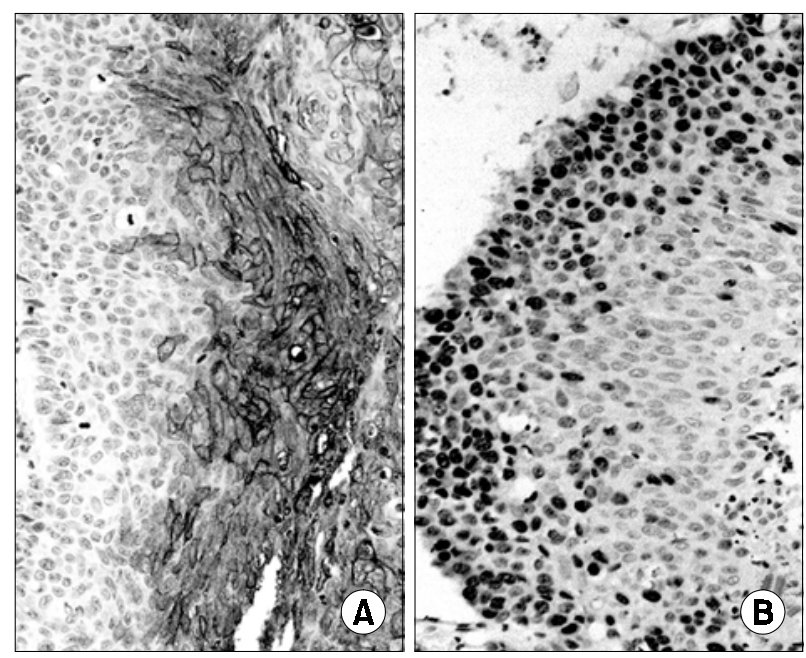

Fig. 4. CD10/NEP expression is prominent in the central more well-differentiated portion of squamous carcinoma (A, $\times$ 200), whereas Ki-67 proliferative activity is mainly found in the less well-differentiated peripheral portion of the squamous carcinoma $(\mathrm{B}, \times 200)$.

(BLPs) and their receptors, and respond to these neuropeptides in an autocrine fashion. CD10/NEP is a major peptidase in the lung and could act as a negative regulator or inhibitor of these autocrine responses (15). Cohen AJ, et al. demonstrated very low or undetectable CD10/NEP expression and activity in both tumors and lung cancer cell lines; a result that supports a crucial role for CD10/NEP in the growth regulation of both SCLC and NSCLC (10). Recent studies have also indicated that there is decreased degradation of autocrine peptides in lung cancer (15). This may be due to low expression of CD10/NEP and other peptides. The normal lung and bronchial epithelium 
express a considerable quantity of CD10/NEP that regulates a number of physiological reactions in the lung such as bronchoconstriction, the increase in the concentration of substance $P$, and the modification of neutrophil physiology $(16 \sim 18)$. In lung cancers, CD10/NEP inactivates all of the peptides responsible for the autocrine/paracrine growth of lung cancer cells, suggesting that low NEP expression in SCLC and NSCLC may be a factor in pulmonary carcinogenesis (19).

We found that CD10/NEP protein expression was markedly reduced or completely absent in a large number of NSCLC (76 $\%)$ and SCLC (80\%) cases. There was no correlation between loss of CD10/NEP expression and most clinicopathologic parameters including smoking history, stage, tumor size, and histologic grade and subtype. However, both NSCLC and SCLC patients under 59 years old revealed a significantly higher loss of CD10/NEP expression than those over 60 years old. To our knowledge, there has been no published report on the significance of age related with the loss of CD10/NEP expression in pulmonary carcinogenesis. We postulate that the tumor cells of younger patients will grow more rapidly than those of older individuals with lung cancer due to a larger loss of CD10/NEP expression on the tumor cell surfaces.

Ganju RK et al. reported that bronchioloalveolar and large cell carcinoma cell lines had low levels of CD10/NEP expression, whereas squamous, adenosquamous, and adenocarcinoma cell lines had higher and more variable levels of the surface enzyme (8). Because they also postulated that the heterogeneity in CD10/NEP expression in specific primary tumors might be correlated with regional variations in tumor cell growth, they evaluated a small number of primary NSCLCs and cell lines for co-expression of CD10/NEP and the proliferating cellular nuclear antigen (PCNA) (8). Their results showed that PCNA expression was more intense in the less well-differentiated basal epithelial cells whereas CD10/NEP expression was more prominent in more well-differentiated luminal lining cells of NSCLCs. In this study, we also observed a similar topographical relationship between CD10/NEP expression and Ki-67 proliferative activity, especially in the squamous cell type of NSCLCs. The central, more well-differentiated, squamous cancer cells disclosed higher CD10/NEP immunoreactivity than the peripheral, less well- differentiated portions that showed no CD10/NEP expression and high proliferating activity as evaluated by Ki-67. This inverse relationship between CD10/NEP and Ki-67 immunostainings in the squamous cell type of NSCLCs suggests that CD10/NEP is itself regulated by cellular proliferation and that in primary NSCLC of the lung, tumor cells with low levels of CD10/NEP may have a proliferative advantage.

Possible mechanisms to explain the low CD10/NEP expression seen in lung cancers include low transcription, mutations, alternate splicing, changes in mRNA stability, and inactivation by chemotherapeutic agents (10). Cohen AJ et al. in their reverse transcription-polymerase chain reaction (RT-PCR) study have shown that tumors often do not exhibit NEP mRNA expression, suggesting that the likely explanation for the low CD10/NEP expression is not mutation or alternative splicing but down-regulation of CD10/NEP transcription $(10,20)$. Therefore, CD10/NEP could indeed act as a tumor suppressor gene. CD10/NEP is localized to chromosome $3 q(21 \sim 27)$ and loss of heterozygosity of $3 q$ has been reported to occur in lung cancer (21). Furthermore, when Tokuhara et al. compared by RT-PCR studies the 5-year survival rates between NEP $(+)$ and NEP (-) NSCLCs, those of the patients with NEP (+) tumors were significantly better than those of NEP $(-)$ tumor patients (9). They therefore considered NEP gene expression as a significant indicator of prognosis.

In a finding similar to that of Cohen $\mathrm{AJ}$ et al., we demonstrated by immunohistochemistry very low or undetectable CD10/NEP expression in both SCLCs and NSCLCs; a result that supports a crucial role for CD10/NEP in the growth regulation of both primary lung carcinomas. Both SCLC and NSCLC cases showing no CD10/NEP expression were smoking-related in $100 \%$ and $76 \%$, respectively, of the cases in this study, although there was no significant difference in the loss of CD10/NEP expression between smokers and non-smokers.

Further studies are necessary to determine the mechanism underlying this reduction or elimination of CD10/NEP expression in lung cancer. In addition, the augmentation of CD10/NEP expression by the delivery of exogenous enzyme or gene constructs may represent an improved approach in the treatment and chemoprevention of lung cancer.

\section{CONCLUSIONS}

We demonstrated very low or undetectable CD10/NEP expression in both SCLCs and NSCLCs by immunohistochemistry, supporting a crucial role for CD10/NEP in pulmonary carcinogenesis. Although there was not any significant relationship between the loss of CD10/NEP expression and the clinicopathologic variables except for age, the CD10/NEP expression was topographically inversely related to the Ki-67 proliferative activity of NSCLC, especially in the squamous cell type. Further molecular studies would be necessary to determine the mechanism of reduced or absent CD10/NEP expression in pulmonary carcinogenesis as a next step in our data.

\section{REFERENCES}

1. Shipp MA, Tarr GE, Chen CY, Switzer SN, Hersh LB, Stein H, Sunday ME, Reinherz EL. CD10/neutral endopeptidase 24.11 hydrolyzes bombesin-like peptides and regulates the growth of small cell carcinomas of the lung. Proc Natl Acad Sci USA 1991;88:10662-10666.

2. Chu P, Arber DA. Paraffin-section detection of CD10 in 505 nonhematopoietic neoplasms. Am J Clin Pathol 2000;113: 374-382.

3. Sunday ME, Hua J, Torday JS, Reyes B, Shipp MA. CD10/ neutral endopeptidase 24.11 in developing human fetal lung. Patterns of expression and modulation of peptide-mediated proliferation. J Clin Invest 1992;90(6):2517-2525.

4. Cuttita F, Carney DN, Mulshine J, Moody TW, Fedorko J, Fischler A, Minna JO. Bombesin-like peptides can function as autocrine growth factors in human small cell lung cancer. Nature (Lond.) 1985;316:823-826.

5. Bunn PA Jr, Chan D, Stewart J, Dienhart D, Tolley R, Jewett PB, Tagawa M. Effects of neuropeptide analogs on calcium flux and proliferation in lung cancer cell lines. Cancer Res 


\section{Cancer Research and Treatment 2002;34(1)}

1994;54:3602-3610

6. Bunn PA Jr, Dienhart DG, Chan D, Puck TT, Tagawa M, Jewett PB, Braunschweiger E. Neuropeptide stimulation of calcium flux in human lung cancer cells. Proc Natl Acad Sci USA 1990;87:2162-2166.

7. Dusser DJ, Djokic TD, Borson DB, Nadel JA. Cigarette smoke induces bronchoconstrictor hyperresponsiveness to substance $\mathrm{P}$ and inactivates airway neutral endopeptidase in the guinea pig. Possible role of free radicals. J Clin Invest 1989;84:900-906.

8. Ganju RK, Sunday M, Tsarwhas DG, Card A, Shipp MA. CD10/NEP in non-small cell lung carcinomas. Relationship to cellular proliferation. J Clin Invest 1994;94:1784-1791.

9. Tokuhara $\mathrm{T}$, Adachi $\mathrm{M}$, Hashida $\mathrm{H}$, Ishida $\mathrm{H}$, Taki $\mathrm{T}$, Higashiyama M, Kodama K, Tachibana S, Sasaki S, Miyake M. Neutral endopeptidase/CD10 and aminopeptidase N/CD13 gene expression as a prognostic factor in non-small cell lung cancer. Jpn J Thorac Cardiovasc Surg 2001;49:489-496.

10. Cohen AJ, Bunn PA, Franklin W, Magill-Solc C, Christa H, Barbara H, Gilman L, Folkvord J, Helm K, Miller YE. Neutral endopeptidase: Variable expression in human lung, inactivation in lung cancer, and modulation of peptide-induced calcium flux. Cancer Res 1996;56:831-839.

11. Matas RA, Kenny J, Turner AJ. The metabolism of neuropeptides; the hydrolysis of peptides, including enkephalins, tachykinins, and their analogues by endopeptidase 24.11 . Biochem J 1984;233:433-440.

12. Borson DB. Roles of neutral endopeptidase in airways. Am J Physiol 1991;266:L212-L225.

13. Johnson AR, Ashton J, Schulz W, Erdos EG. Neutral metalloendo-peptidase in human lung tissue and cultured cells. Am Rev Respir Dis 1985;132:564-568.
14. Kim MK, Kim HK, Kim I, Han J, Huh SJ, Ahn YH, Kim DY, Shim YM. p53 expression in non-small cell lung cancer. Its relationship to the clinical prognostic factor and smkoing history. J Korean Cancer Assoc 1999;31:1219-1226.

15. Bunn PA Jr, Barbara AH, Brenner DG, Chan DC, Dykes DJ, Cohen AJ, Miller YE. Effects of recombinant neutral endopeptidase (EC 3.4.24.11) on the growth of lung cancer cell lines in vitro and in vivo. Clin Cancer Res 1998;4:28492858.

16. Stimler-Gerard NP. Neutral endopeptidase-like enzyme controls the contractile activity of substance $\mathrm{P}$ in guinea pig lung. $\mathrm{J}$ Clin Invest 1992;90:2517-2525.

17. Martins MA, Shore SA, Gerard NP, Gerard C, Drazen JM. Peptidase modulation of pulmonary effects of tachykinins in tracheal superfused guinea pig lungs. J Clin Invest 1990;85: 170-176.

18. Shipp MA, Stefano GB, Switzer SN, Griffin JD, Reinherz EL. CD10(CALLA) neutral endopeptidase 24.11 modulates inflammatory peptide-induced changes in neutrophil morphology: migration, and adhesion proteins and is itself regulated by neutrophil activation. Blood 1991;78:1834-1841.

19. Cohen AJ, Franklin WA, Magill C, Sorenson J, Miller YE. Low neutral endopeptidase levels in bronchoalveolar lavage fluid of lung cancer patients. Am J Respir Crit Care Med 1999;159:907-910.

20. Cohen AJ, Gilman LB, Moore M, Franklin WA, Miller YE. Inactivation of neutral endopeptidase in lung cancer. Chest 1996;109(Suppl):12S-13S.

21. Minna JD. The molecular biology of lung cancer pathogenesis. Chest 1993;103(Suppl):A449s-456s. 